02

\title{
Спектрально-люминесцентные свойства стекол системы
} $\left(\mathrm{Y}_{1-x} \mathrm{Yb}_{x}\right)_{2} \mathrm{O}_{3}-\mathrm{Al}_{2} \mathrm{O}_{3}-\mathrm{B}_{2} \mathrm{O}_{3}-\mathrm{SiO}_{2}+\mathrm{Cr}_{2} \mathrm{O}_{3}+\mathrm{Na}_{2} \mathrm{O}$

\author{
(C) Г.Е. Малашкевич ${ }^{1}$, В.В. Ковгар ${ }^{1}$, А.А. Романенко ${ }^{1}$, И.И. Азарко ${ }^{2}$, В.Н. Сигаев ${ }^{3}$, Н.В. Голубев ${ }^{3}$, \\ М.3. Зиятдинова ${ }^{3}$, Е.С. Игнатьева ${ }^{3}$, С.А. Бахрамов ${ }^{4}$ \\ ${ }^{1}$ Институт фризики им. Б.И. Степанова НАН Беларуси, \\ 220072 Минск, Республика Беларусь \\ ${ }^{2}$ Белорусский государственный университет, \\ 220050 Минск, Республика Беларусь \\ ${ }^{3}$ Российский химико-технологический университет им. Д.И. Менделеева, \\ 125047 Москва, Россия \\ ${ }^{4}$ Институт ионно-плазменных и лазерных технологий им. У.А. Арифова АН Республики Узбекистан, \\ 100125 Ташкент, Узбекистан \\ e-mail: g.malashkevich@ifanbel.bas-net.by
}

Поступила в редакцию 03.08.2021 г.

В окончательной редакции 03.08.2021 r.

Принята к публикации 17.08.2021 г.

Синтезированы плавленые иттрий-алюмоборатные стекла, легированные иттербием, кремнием, хромом и натрием. С помощью спектрально-люминесцентного и ЭПР исследований выяснено влияние матрицы на „спектроскопическое поведение“ ионов хрома и эффективность сенсибилизации ими люминесценции $\mathrm{Yb}^{3+}$. Установлено, что (1) хром в бесщелочных стёклах реализуется преимущественно в степени окисления $\mathrm{Cr}(\mathrm{III})$ с заметной примесью $\mathrm{Cr}(\mathrm{IV})$ и $\mathrm{Cr}(\mathrm{V})$, (2) частичное замещение $\mathrm{Al}_{2} \mathrm{O}_{3}$ либо $\mathrm{B}_{2} \mathrm{O}_{3}$ на $\mathrm{SiO}_{2}$, а также $\mathrm{Y}_{2} \mathrm{O}_{3}$ на $\mathrm{Yb}_{2} \mathrm{O}_{3}$ в различной степени отражается на относительной концентрации оптических центров ионов хрома, (3) при введении щёлочи формируются центры $\mathrm{Cr}(\mathrm{VI})$ за счёт окисления ионов хрома с более низким зарядом и в первую очередь четырёхкоординированных $\mathrm{Cr}^{4+}$ и $\mathrm{Cr}^{5+}$, (4) основной вклад в сенсибилизацию люминесценции ионов $\mathrm{Yb}^{3+}$ вносят ионы $\mathrm{Cr}^{3+}$, а ионы $\mathrm{Cr}^{4+}$ и в меньшей степени $\mathrm{Cr}^{5+}$ играют роль тушителей люминесценции и внутреннего фильтра. Обнаружена сенсибилизация люминесценции $\mathrm{Yb}^{3+}$ через полосу переноса заряда в $\mathrm{Cr}(\mathrm{VI})$. В щелочном стекле, легированном $\mathrm{Cr}$ и $\mathrm{Yb}$, при возбуждении через сенсибилизатор реализован квантовый выход люминесценции, составляющий $32 \%$, и рассмотрены условия его повышения. Показано, что температурное тушение люминесценции $\mathrm{Cr}-\mathrm{Yb}$-содержащих стекол существенно меньше, чем Сr-содержащих.

Ключевые слова: ЭПР-спектры, ионы хрома и иттербия, квантовый выход люминесценции, сенсибилизация и тушение люминесценции.

DOI: $10.21883 / \mathrm{OS} .2022 .01 .51908 .28-21$

\section{Введение}

Стёкла, соактивированные ионами $\mathrm{Cr}^{3+}$ и $\mathrm{Ln}^{3+}$, начали интенсивно исследоваться с начала 80-х годов прошлого века, когда было предложено использовать их в качестве люминесцентных концентраторов солнечного излучения [1] и обнаружено существенное повышение эффективности генерации накачиваемых лампами эрбиевых лазеров на $\mathrm{Yb}-\mathrm{Er}-$ содержащих стёклах при дополнительной соактивации ионами $\mathrm{Cr}^{3+}[2-4]$. Хотя с появлением полупроводниковых источников селективной накачки интерес к использованию последних для сенсибилизации люминесценции „лазерных“ ионов радикально упал, интенсивность исследований $\mathrm{Cr}$ - и $\mathrm{Cr}-\mathrm{Ln}$-содержащих оптических материалов практически не снизилась. Причина такой ситуации нам видится в высоком „спектроскопическом потенциале“ ионов хрома, обусловленном возможностью существенного влияния состава, структуры и условий синтеза матрицы на зарядовое состояние этих ионов и их спектры [5-10], в стремлении получения на них перестраиваемой генерации, а также перспективном для лазеров с солнечной накачкой [11] и указанных выше люминесцентных концентраторов сочетании широких полос поглощения в УФ и видимой областях спектра и люминесценции в красной и ближней ИК. Особый интерес, по нашему мнению, представляет исследование природы оптических центров хрома и процессов сенсибилизации ими люминесценции ионов $\mathrm{Ln}^{3+}$ в иттрий-алюмоборатных стёклах с составом вблизи стехиометрии хантита, обеспечивающих минимальное расстояние между редкоземельными ионами $\approx 6.7 \AA[12]$, что способствует пониженному концентрационному тушению их люминесценции и радикальному ослаблению кооперативных взаимодействий. В частности, недавно [13] было установлено, что квантовый выход люминесценции ионов $\mathrm{Yb}^{3+}$ в таких стёклах, не подвергнутых принудительной дегидратации, составляет $\approx 80 \%$ при концентрации $\mathrm{Yb}_{2} \mathrm{O}_{3}$, равной $0.5 \mathrm{~mol} \%$, и 
снижается до $\approx 60 \%$ при увеличении последней до $2 \mathrm{~mol} \%$. Учитывая возможность стабилизации ионов хрома в кварцевых стёклах в состоянии $\mathrm{Cr}^{5+}$, проявляющем достаточно интенсивную широкополосную люминесценцию в красной области спектра $[9,10,14,15]$, в настоящей работе была поставлена задача исследовать влияние дополнительного введения кремнезёма и щелочных оксидов на спектрально-люминесцентные свойства хантитоподобных стекол, соактивированных ионами хрома и иттербия.

\section{Эксперимент}

Исследуемые стекла синтезировались путём плавления шихты в лабораторной печи сопротивления с $\mathrm{SiC}$ нагревателями в платиновом тигле при $T \approx 1480^{\circ} \mathrm{C}$ на воздухе в течение $60 \mathrm{~min}$. В качестве исходных компонентов использовали $\mathrm{Y}_{2} \mathrm{O}_{3}$ (осч), $\mathrm{Al}(\mathrm{OH})_{3}$ (чда), $\mathrm{H}_{3} \mathrm{BO}_{3}, \mathrm{Yb}_{2} \mathrm{O}_{3}$ (осч), аморфный $\mathrm{SiO}_{2}$ (осч), $\mathrm{Cr}_{2} \mathrm{O}_{3}$ (хч), $\mathrm{Na}_{2} \mathrm{CO}_{3}$ (хч). Плотность синтезированных стекол $(\rho)$ определялась методом гидростатического взвешивания, показатель преломления $(n)$ измерялся на рефрактометpe Aббе NAR-3T при $\lambda=589.3 \mathrm{~nm}$, а относительная концентрация примесных $\mathrm{OH}^{-}$-групп оценивалась по пиковой величине коэффициента поглощения в области основного колебания связи $\mathrm{O}-\mathrm{H}\left(k_{\mathrm{OH}}\right)$, которая определялась по методике [13]. Данные параметры и составы (по шихте) синтезированных стёкол сведены в табл. 1.

Исследование электронного парамагнитного резонанca (ЭПР) проводилось на спектрометре E-112 (Varian, USA), работающем в Х-диапазоне при комнатной температуре. Концентрация парамагнитных центров определялась методом сравнения с эталоном, в качестве которого использовался аттестованный образец угольного порошка с определенной концентрацией центров, gфактор определялся по известным значениям g-факторов эталонных линий в спектре ЭПР ионов $\mathrm{Mn}^{2+}$ в порошке $\mathrm{MgO}$ и прямыми измерениями частоты СВЧ излучения и величины напряженности магнитного поля в условиях резонанса.

Спектры светоослабления (ССО) синтезированных стекол записывались на спектрофотометре Cary-500 (Varian, USA-Australia), а спектры люминесценции (СЛ) и возбуждения люминесценции (СВЛ) - на спектрофлуориметре Fluorolog-3 (HORIBA Scientific, USA). В качестве детектора в измерениях СВЛ в УФ и видимой областях спектра использовался Пельтье-охлаждаемый ФЭУ PPD-850 (HORIBA Scientific), в ближней ИК области спектра - охлаждаемый жидким азотом ФЭУ R5509-73 (Hamamatsu, Japan). Для регистрации СЛ в видимой области спектра и до $1050 \mathrm{~nm}$ использовалась Пельтье-охлаждаемая кремниевая ПЗС-матрица Syncerity (HORIBA Scientific). Полученные СЛ и СВЛ исправлялись с учетом спектральной чувствительности системы регистрации и распределения спектральной плотности возбуждающего излучения соответственно и выражались в виде зависимости числа квантов на единичный интервал длин волн $(d N / d \lambda)$ от $\lambda$.

Квантовый выход люминесценции $(\eta)$ определялся по хорошо известной методике с помощью соотношения

$$
\eta=\eta_{e t} S_{x} A_{e t} I_{x} n_{x}^{2} / S_{e t} A_{x} I_{e t} n_{e t}^{2}
$$

где $S$ - площадь под СЛ; $A-$ поглощение образца в \%; $I$ - „квантовая“ интенсивность возбуждающего света; индексы ,„“ и „енt“ относятся к испытываемому образцу и эталону соответственно. В качестве эталона использовалось паспортизированное неодимовое стекло ГЛС-2 с абсолютным квантовым выходом люминесценции $67 \%$ и показателем преломления 1.526 при $\lambda=589 \mathrm{~nm}$.

Для измерения кинетики затухания люминесценции в качестве источника возбуждения использовался импульсный светодиод SpectraLED-390 (HORIBA Scientific) с длиной волны излучения $389 \mathrm{~nm}$ и длительностью импульса по полуширине $50 \mu \mathrm{s}$. Регистрация осуществлялась при $\lambda_{\text {reg }}=976 \mathrm{~nm}$ с помощью ФЭУ R5509-73. Полученные кривые аппроксимировались двумя экспонентами в программе DAS6 (HORIBA Scientific):

$$
F(t)=A+B_{1} e^{-t / \tau_{1}}+B_{2} e^{-t / \tau_{2}},
$$

где процентный вклад каждой из компонент (по интенсивности) рассчитывался как

$$
B_{i}=B_{i} /\left(B_{1}+B_{2}\right)
$$

а среднее время жизни определялось по формуле

$$
\langle\tau\rangle=B_{1} \tau_{1}+B_{2} \tau_{2}
$$

Температурные измерения проводились с помощью термостатируемого кюветного держателя Luma 40S (Quantum Northwest, USA) в кварцевой кювете, заполненной дистиллированной водой. Временной интервал между измерениями обеспечивал выравнивание температуры последней и образца.

\section{Результаты}

На рис. 1 приведены ЭПР-спектры стекла состава $(\mathrm{mol} \%) \quad 9.5 \mathrm{Y}_{2} \mathrm{O}_{3}-0.5 \mathrm{Yb}_{2} \mathrm{O}_{3}-30 \mathrm{Al}_{2} \mathrm{O}_{3}-60 \mathrm{~B}_{2} \mathrm{O}_{3}+5 \mathrm{Na}_{2} \mathrm{O}$ (кривая 0) и образца 3. Здесь и ниже номера кривых соответствуют номерам образцов стекол в табл. 1 . Видно, что Сr-содержащее стекло характеризуется относительно узкими сигналами при $g \approx 1.97$ и 4.8 и широким при $g \approx 5.33$. Перечисленные сигналы наблюдаются в спектрах всех стекол, приведенных в табл. 1, различаясь главным образом относительными интенсивностями и спектральной шириной сигнала при $g \approx 4.8$. Экспериментальные значения $g$-фактора, ширины $(\Delta H)$ и относительной интенсивности $(I)$ сигналов, а также парциальной концентрации спинов $\left(N_{i}\right)$ для стекол с одинаковой концентрацией $\mathrm{Cr}_{2} \mathrm{O}_{3}(0.2 \mathrm{mass} \%)$ сведены в табл. 2. Как видно из 
Таблица 1. Составы синтезированных стекол, их плотность, показатель преломления и пиковый коэффициент поглощения примесных $\mathrm{OH}^{-}$-групп

\begin{tabular}{|c|c|c|c|c|c|c|c|c|c|c|}
\hline \multirow[t]{2}{*}{ Sample } & $\mathrm{Y}_{2} \mathrm{O}_{3}$ & $\mathrm{Yb}_{2} \mathrm{O}_{3}$ & $\mathrm{Al}_{2} \mathrm{O}_{3}$ & $\mathrm{~B}_{2} \mathrm{O}_{3}$ & $\mathrm{SiO}_{2}$ & $\mathrm{Cr}_{2} \mathrm{O}_{3}$ & $\mathrm{Na}_{2} \mathrm{O}$ & \multirow{2}{*}{$\begin{array}{c}\rho, \\
\mathrm{g} / \mathrm{cm}^{3}\end{array}$} & \multirow[t]{2}{*}{$n$} & \multirow{2}{*}{$\begin{array}{c}k_{\mathrm{OH}}, \\
\mathrm{cm}^{-1}\end{array}$} \\
\hline & \multicolumn{5}{|c|}{$\mathrm{mol} \%$} & \multicolumn{2}{|c|}{$\operatorname{mass} \%$} & & & \\
\hline 1 & 10.0 & - & 30.0 & 60.0 & - & 0.2 & - & $2.82(3)$ & $1.61(0)$ & 1.30 \\
\hline 2 & 10.0 & - & 25.0 & 60.0 & 5.0 & 0.1 & - & 2.774 & 1.5999 & 2.38 \\
\hline 3 & 10.0 & - & 25.0 & 60.0 & 5.0 & 0.2 & - & 2.768 & 1.6020 & 1.74 \\
\hline 4 & 10.0 & - & 25.0 & 60.0 & 5.0 & 0.2 & 2.0 & 2.718 & 1.5875 & 1.95 \\
\hline 5 & 10.0 & - & 25.0 & 60.0 & 5.0 & 0.2 & 4.0 & 2.697 & 1.5761 & 2.42 \\
\hline 6 & 9.0 & 1.0 & 30.0 & 60.0 & - & 0.2 & - & $2.88(8)$ & $1.60(5)$ & 1.42 \\
\hline 7 & 9.0 & 1.0 & 25.0 & 60.0 & 5.0 & 0.2 & - & 2.826 & 1.5982 & 1.49 \\
\hline 8 & 8.0 & 2.0 & 30.0 & 60.0 & - & 0.2 & - & $2.93(5)$ & $1.60(6)$ & 1.42 \\
\hline 9 & 8.0 & 2.0 & 25.0 & 60.0 & 5.0 & 0.1 & - & 2.872 & 1.5993 & 1.60 \\
\hline 10 & 8.0 & 2.0 & 30.0 & 55.0 & 5.0 & 0.2 & - & 2.919 & 1.6043 & 2.47 \\
\hline 11 & 8.0 & 2.0 & 30.0 & 50.0 & 10.0 & 0.2 & - & $2.94(2)$ & $1.60(8)$ & 2.41 \\
\hline 12 & 8.0 & 2.0 & 30.0 & 45.0 & 15.0 & 0.2 & - & 2.964 & 1.6107 & 2.47 \\
\hline 13 & 8.0 & 2.0 & 25.0 & 60.0 & 5.0 & 0.2 & 2.0 & 2.823 & 1.5863 & 2.53 \\
\hline 14 & 8.0 & 2.0 & 25.0 & 60.0 & 5.0 & 0.2 & 4.0 & 2.780 & 1.5752 & 2.91 \\
\hline 15 & 8.0 & 2.0 & 25.0 & 60.0 & 5.0 & 0.2 & 8.0 & 2.821 & 1.5617 & 2.72 \\
\hline
\end{tabular}

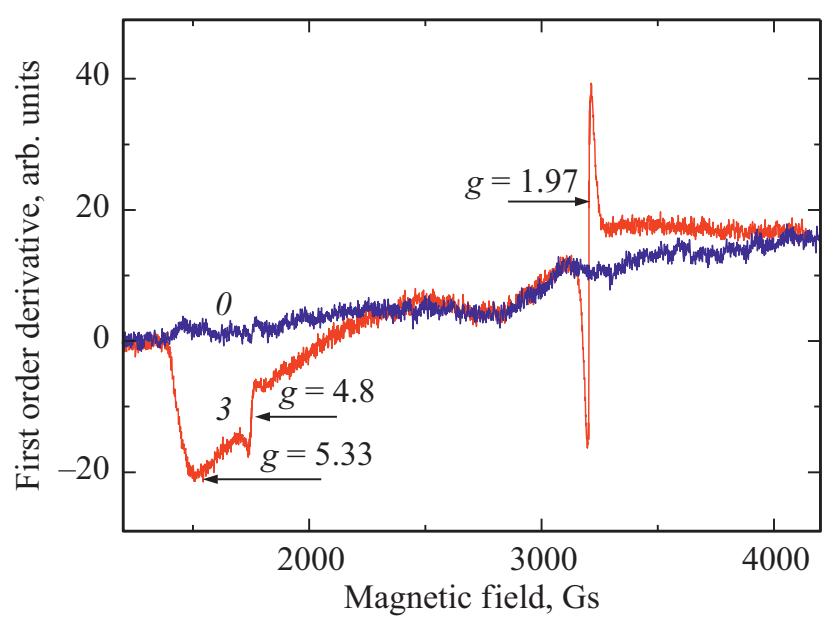

Рис. 1. Типичные ЭПР-спектры исследованных стекол. Пояснения в тексте.

этой таблицы, частичное замещение $\mathrm{Al}_{2} \mathrm{O}_{3}$ на $\mathrm{SiO}_{2}$ сопровождается увеличением $N_{1}$ и $N_{2}$ (ср. образцы 1 с 3 и 8 с 7), при этом значение $I$ незначительно снижается для стекол без $\mathrm{Yb}$ (cp. образцы 1 и 3) и многократно возрастает при его наличии (ср. образцы 8 и 7). При замещении $\mathrm{B}_{2} \mathrm{O}_{3}$ данной тенденции не наблюдается (ср. образцы 8, 10-12). Замещение Y на $\mathrm{Yb}$ в бескремнезёмном стекле слабо влияет на $N_{1}$ и $N_{2}$, однако значение $I$ проходит через экстремум (ср. образцы 1, 6, 8), в то время как в кремнезёмном стекле такое замещение сопровождается существенным ростом $N_{1}$ и $I$ при незначительном снижении $N_{2}$ (ср. образцы 3 и 7). Ощелачивание стекол, в которых $\mathrm{Al}_{2} \mathrm{O}_{3}$ частично замещён на $\mathrm{SiO}_{2}$, сопровождается снижением $N_{2}$ и прохождением $N_{1}$ и $I$ через экстремум (ср. образцы 3-5 и $13-15)$.

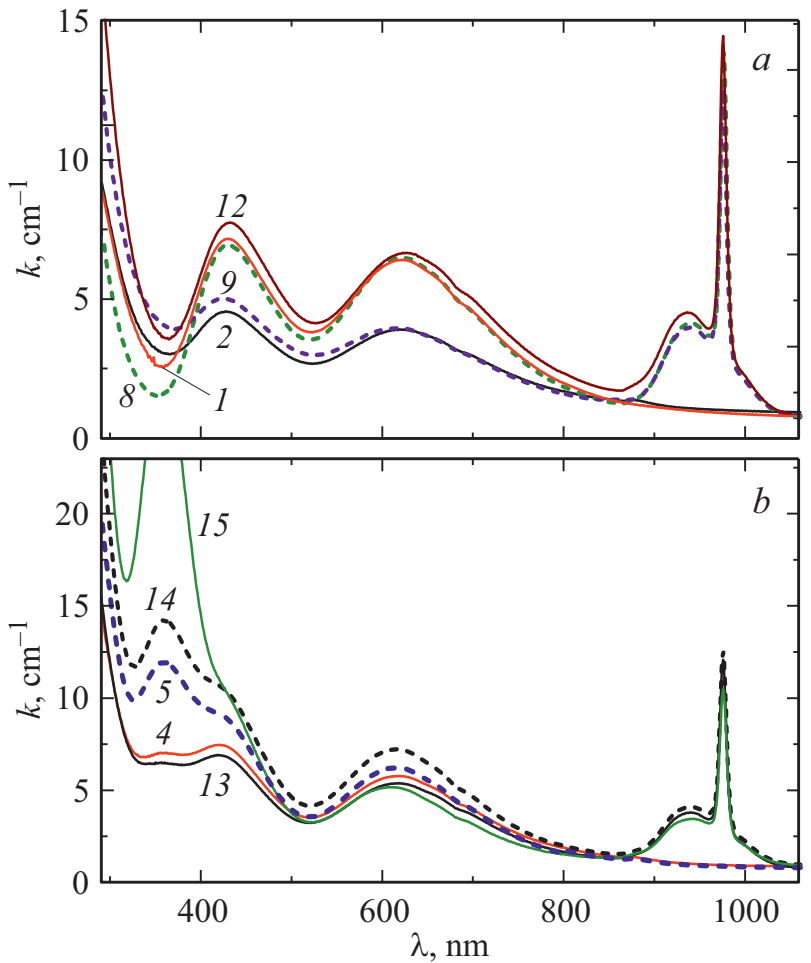

Рис. 2. Спектры светоослабления бесщелочных $(a)$ и щелочных $(b)$ стекол. Пояснения в тексте.

На рис. 2 приведены ССО исследованных стекол. Здесь ряд спектров опущен по причине их практически полного совпадения с изображёнными: кривая 1 совпадает с кривой 3, 6 с 7,12 с 10 и 11. Как видно, в спектрах бесщелочных Cr-содержащих стекол присутствуют широкие слабоструктурные полосы с максимумами при $\lambda_{\max } \approx 430$ и $620 \mathrm{~nm}$. Соактивация этих стекол иона- 


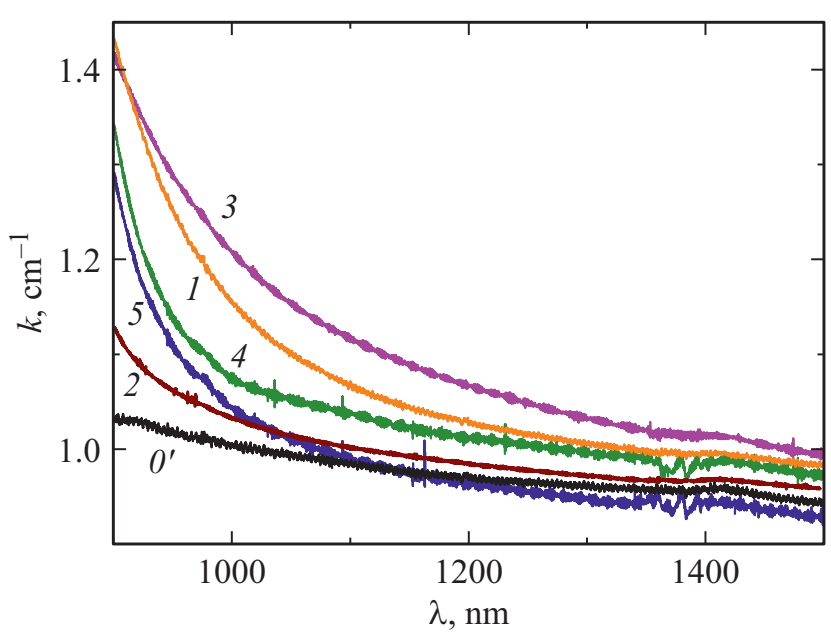

Рис. 3. Спектры светоослабления в ближней ИК области. Пояснения в тексте.

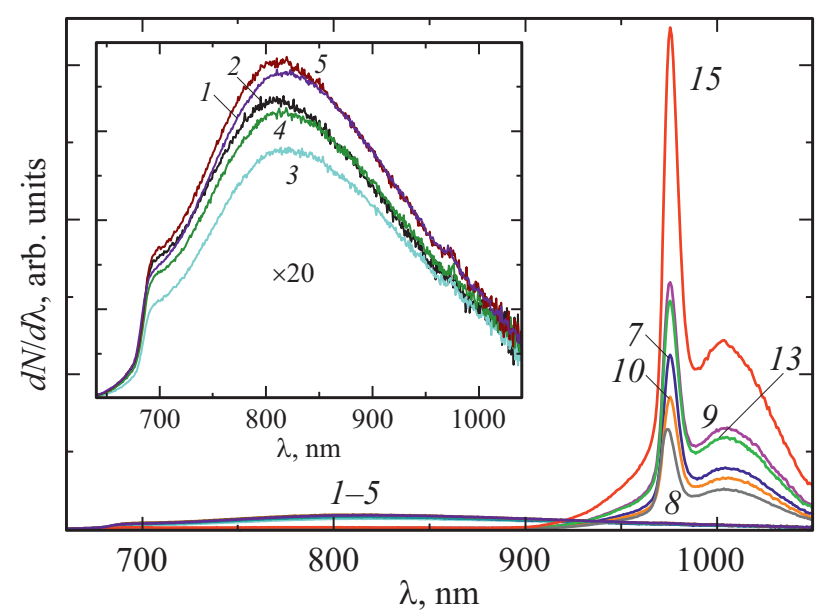

Рис. 4. Спектры люминесценции. $\lambda_{\mathrm{exc}}=600 \mathrm{~nm}$. Пояснения в тексте.

ми $\mathrm{Yb}^{3+}$ сопровождается появлением дополнительной структурной полосы с $\lambda_{\max } \approx 976 \mathrm{~nm}$. Введение кремнезёма практически не отражается на данных спектрах. Ощелачивание таких стекол сопровождается появлением дополнительной диффузной полосы при $\lambda \approx 360 \mathrm{~nm}$, интенсивность которой повышается с увеличением концентрации $\mathrm{Na}_{2} \mathrm{O}$ (ср. кривые $13,14,15$ ), и заметным снижением значений $k$ в полосе с $\lambda_{\max } \approx 620 \mathrm{~nm}$ (cp. кривые 1 и 12 с кривыми 4, 5 и 14, 15 соответственно).

На рис. 3 приведены ССО в области длинноволнового крыла полосы поглощения с $\lambda_{\max } \approx 620 \mathrm{~nm}$ Сr-содержащих стекол, записанные со скоростью $60 \mathrm{~nm} / \mathrm{min}$ и шагом $0.1 \mathrm{~nm}$. Здесь кривая $O^{\prime}$ принадлежит неактивированному стеклу состава (mol\%) $10 \mathrm{Y}_{2} \mathrm{O}_{3}-30 \mathrm{Al}_{2} \mathrm{O}_{3}-60 \mathrm{~B}_{2} \mathrm{O}_{3}$. Видно, что это крыло тянется по крайней мере до $1400 \mathrm{~nm}$. Введение в бесщелочное стекло кремнезёма сопровождается заметным повышением $k$ в области 1000-1300 nm (ср. кривые 1 и 3). Двукратное уменьшение концентрации $\mathrm{Cr}$ в таком

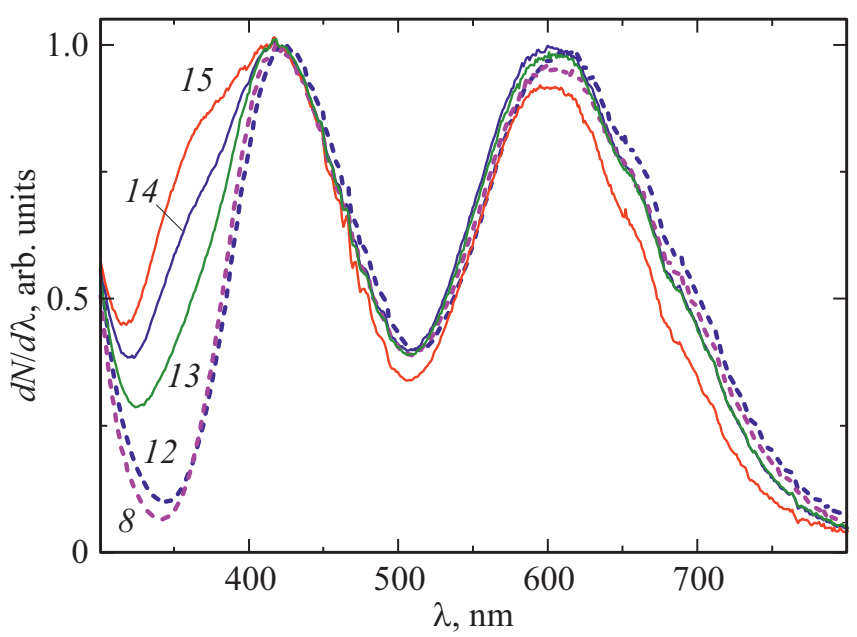

Pис. 5. Спектры возбуждения люминесценции. $\lambda_{\text {rec }}=1010 \mathrm{~nm}$. Пояснения в тексте.

стекле ведёт к непропорционально большему снижению интенсивности ИК поглощения (ср. кривые 3 и 2). Дополнительное введение в подобные стёкла $\mathrm{Na}_{2} \mathrm{O}$ также сопровождается значительным снижением этого поглощения (ср. кривые 3-5).

На рис. 4 изображены СЛ, приведенные к одинаковому числу поглощённых квантов при длине волны возбуждения $\lambda_{\mathrm{exc}}=600 \mathrm{~nm}$. Видно, что СЛ Cr-содержащих стекол характеризуется широкой $(\Delta \lambda \approx 230 \mathrm{~nm})$ полосой с $\lambda_{\text {max }} \approx 810 \mathrm{~nm}$ и рельефным плечом при $\lambda \approx 700 \mathrm{~nm}$. Изменение относительной интенсивности этой полосы в зависимости от состава стекла не превышает $30 \%$ (cp. кривые 1-5 на вставке). При соактивации $\mathrm{Cr}$ содержащих стекол ионами $\mathrm{Yb}^{3+}$ наблюдается многократное ослабление данной полосы и появление полосы люминесценции указанных ионов. Минимальная интенсивность последней реализуется для бескремнезёмного стекла (кривая 8) и возрастает примерно на 25\% при введении $5 \mathrm{~mol} \% \mathrm{SiO}_{2}$ (кривая 10). Увеличение концентрации $\mathrm{SiO}_{2}$ до $15 \mathrm{~mol} \%$ практически не отражается на интенсивности интегральной люминесценции такого стекла - кривая 12 в пределах ошибки эксперимента совпадает с кривой 10 и на рисунке не приведена. В то же время эта интенсивность существенно возрастает по мере увеличения концентрации $\mathrm{Na}_{2} \mathrm{O}$ (ср. кривые $10,13,15)$. Здесь следует обратить внимание на заметное увеличение интенсивности люминесценции исследованных стекол при снижении концентрации $\mathrm{Yb}$ (cp. кривые 10 и 7) либо $\mathrm{Cr}$ (cp. кривые 10 и 9). Отметим также, что дополнительные полосы люминесценции этих стекол в ближней ИК области $(1.0-2.0 \mu \mathrm{m})$ отсутствуют, а при $\lambda_{\text {ехс }}=470 \mathrm{~nm}$ наблюдается почти на три порядка менее интенсивная широкая полоса с $\lambda_{\max } \approx 550 \mathrm{~nm}$.

Квантовый выход люминесценции образца 15, определённый с использованием формулы (1) при $\lambda_{\text {exc }}=585 \mathrm{~nm}$, составил $32 \%$. Используя данные рис. 4, несложно определить, что значения $\eta$ для остальных 
Таблица 2. Значения $g$-фактора, ширины $\Delta H$ и относительной интенсивности $I$ сигнала, а также парциальной концентрации спинов $N_{i}$

\begin{tabular}{c|c|c|c|c|c}
\hline \multirow{2}{*}{ Sample } & \multicolumn{2}{|c|}{$g=1.97$} & \multicolumn{2}{|c}{$g \approx 4.8$} & \multicolumn{2}{c}{$g \approx 5.33$} \\
\cline { 2 - 6 } & $\Delta H$, Gs & $N_{1}, 10^{17}$ spin/g & $\Delta H$, Gs & $N_{2}, 10^{17}$ spin/g & $I$, arb. units \\
\hline 1 & 35 & 0.48 & 40 & 6.70 & 1.11 \\
3 & 35 & 3.17 & 60 & 19.70 & 1.00 \\
4 & 35 & 5.35 & 50 & 16.00 & 1.43 \\
5 & 35 & 4.95 & 45 & 8.20 & 1.05 \\
6 & 35 & 0.34 & 55 & 6.05 & 1.43 \\
7 & 35 & 6.20 & 50 & 18.00 & 1.52 \\
8 & 35 & 0.72 & 50 & 10.45 & 0.30 \\
10 & 35 & 0.73 & 50 & 6.10 & 0.81 \\
11 & 35 & 0.67 & 60 & 12.00 & 0.71 \\
12 & 35 & 0.72 & 50.95 & 0.71 \\
13 & 35 & 1.90 & 40 & 8.02 & 0.52 \\
14 & 35 & 3.00 & 3.25 & 0.86 \\
15 & 35 & 1.75 & &
\end{tabular}

Таблица 3. Парциальные длительности экспоненциальных стадий затухания люминесценции $\left(\tau_{1}, \tau_{2}\right)$, относительные амплитуды $\left(B_{i}\right)$, средняя длительность $(\langle\tau\rangle)$ и критерий согласия Пирсона $\left(\chi^{2}\right)$

\begin{tabular}{c|c|c|c|c}
\hline Sample & $\tau_{1}, \tau_{2}, \mu \mathrm{s}$ & $B_{1}, B_{2}$ & $\langle\tau\rangle, \mu \mathrm{s}$ & $\chi^{2}$ \\
\hline 7 & 151,325 & $0.42,0.58$ & 253 & 1.04 \\
8 & 97,230 & $0.22,0.78$ & 206 & 1.03 \\
9 & 179,357 & $0.31,0.69$ & 302 & 1.04 \\
13 & 135,287 & $0.41,0.59$ & 224 & 1.06 \\
15 & 179,397 & $0.54,0.46$ & 279 & 1.03
\end{tabular}

образцов составляют следующие величины: $6.4 \%$ (образец 1), 5.8\% (2), 4.9\% (3), 5.7\% (4), 6.6\% (5), $11.2 \%$ (7), 7.0\% (8), 17.0\% (9), 8.9\% (10-12), 15.6\% (13).

На рис. 5 изображены СВЛ ионов $\mathrm{Yb}^{3+}$ в $\mathrm{Cr}-\mathrm{Yb}-$ содержащих стёклах, полученные при длине волны регистрации $\lambda_{\text {rec }}=1010 \mathrm{~nm}$ и приведенные в максимуме к единице. Видно, что спектры бесщелочных стекол (образцы 6-12) представлены двумя широкими полосами с $\lambda_{\max } \approx 420 \mathrm{~nm}$ и $610 \mathrm{~nm}$ с неглубокими впадинами на длинноволновой полосе при $\lambda \approx 645 \mathrm{~nm}$ и $680 \mathrm{~nm}$. Следует отметить, что спектры таких стекол с различными концентрациями $\mathrm{SiO}_{2}$ (образцы 10-12) и $\mathrm{Yb}_{2} \mathrm{O}_{3}$ (образцы 6 и 8) практически совпадают, и поэтому представлены по одной кривой (кривые 12 и 8 соответственно). Спектры щелочных стекол характеризуются появлением дополнительного плеча при $\lambda \approx 360 \mathrm{~nm}$, интенсивность которого изменяется симбатно концентрации $\mathrm{Na}_{2} \mathrm{O}$ (см. кривые 13-15).

Кинетика затухания люминесценции ионов $\mathrm{Yb}^{3+}$ в исследованных стёклах имеет неэкспоненциальный характер. Значения основных параметров, полученных с помощью формул (2)-(4) при описанных в разделе „Эксперимент“ условиях и характеризующих этот процесс, для ряда стекол сведены в табл. 3. Здесь следует от-

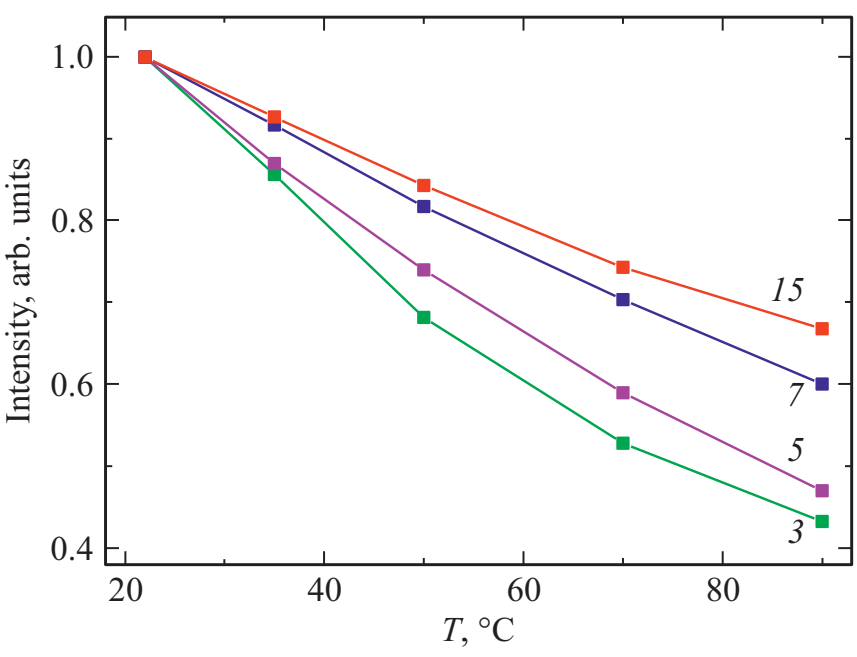

Рис. 6. Зависимость интегральной интенсивности люминесценции $\mathrm{Cr}-$ и $\mathrm{Cr}-\mathrm{Yb}$ - содержащих стекол от их температуры. $\lambda_{\mathrm{exc}}=600 \mathrm{~nm}$. Пояснения в тексте.

метить, что используемая аппроксимация кинетических кривых затухания люминесценции двумя экспонентами является формальной и позволяет судить лишь о степени их неэкспоненциальности. При этом незначительное отклонение критерия $\chi^{2}$ от единицы свидетельствует о приемлемой точности подгонки расчётной кривой к экспериментальной.

На рис. 6 изображена зависимость интегральной интенсивности люминесценции ряда стекол от их температуры. Видно, что в наибольшей степени с ростом температуры падает интенсивность люминесценции бесщелочного Cr-содержащего стекла (кривая 3). Введение щёлочи несколько уменьшает амплитуду такого падения (кривая 5). Для $\mathrm{Cr}-\mathrm{Yb}$-содержащих стекол температурное снижение интенсивности люминесценции существенно слабее (ср. кривые 3 и 5 с кривыми 7 и 15). Заметим, что 
для образцов 8-14 экспериментальные значения лежат в пределах, ограниченных кривыми 7 и 15. Для Ybсодержащих стекол как бесщелочных, так и щелочных интенсивность люминесценции в исследованном температурном диапазоне снижается не более чем на $3 \%$, незначительно превышая ошибку эксперимента (2\%).

\section{Обсуждение}

Согласно литературным данным [16-22], ЭПР-сигнал на рис. 1 при $g \approx 1.97$ можно приписать ионам $\mathrm{Cr}^{5+}$ и связанным обменным взаимодействием парам октаэдрически координированных ионов $\mathrm{Cr}^{3+}$ либо изолированным центрам $\mathrm{Cr}^{3+}$ кубической симметрии, сигнал при $g \approx 4.8$ - изолированным ионам $\mathrm{Cr}^{3+}$ в сильно искажённом октаэдрическом окружении, а широкий сигнал при $g \approx 5.33$ - изолированным „октаэдрическим“ $\mathrm{Cr}^{3+}$ ромбической симметрии в сильном локальном поле. В [13] показано, что в хантитоподобном стекле концентрация парных $\mathrm{Yb}-\mathrm{Yb}$-центров примерно на два порядка меньше, чем в высококремнезёмном гель-стекле. Нет оснований предполагать и формирование в исследованном стекле заметной доли „кубических“ центров $\mathrm{Cr}^{3+}$. Поэтому можно пренебречь вкладом последних и с учётом относительно низкой концентрации хрома указанных обменно-связанных пар $\mathrm{Cr}^{3+}-\mathrm{Cr}^{3+}$ в ЭПРсигнал при $g \approx 1.97$. Определяя концентрацию атомов $\mathrm{Cr}$ в этих стёклах по формуле $N_{\mathrm{Cr}}=0.02 N_{A} P / M$, где $N_{A}, p$ и $M$ - число Авогадро, mass $\% \mathrm{Cr}_{2} \mathrm{O}_{3}$ и его молярная масса соответственно, находим, что она составляет $\approx 15.84 \cdot 10^{18}$ atom $/ g$. Это позволяет с учётом данных табл. 2 оценить максимальные доли ионов $\mathrm{Cr}^{5+}$ и сильно искажённых полиэдров $\left[\mathrm{CrO}_{6}\right]^{9-}$ в данных стёклах на уровне $3.9 \%$ (образец 7) и 12.4\% (образец 3 ) соответственно от общей концентрации хрома. Менее однозначной является оценка доли центров с $g \approx 5.33$, так как из-за большой ширины и необычной формы ЭПРсигнала оказалось проблематичным корректное определение концентрации спинов. Тем не менее, исходя из гораздо большей ширины и интенсивности этого сигнала по сравнению с близким сигналом с $g \approx 4.8$, можно утверждать, что для большинства стекол доля соответствующих центров является подавляющей. Исключение составляет, пожалуй, лишь образец 15 , который характеризуется минимальными значениями $N_{1}+N_{2}$ и $I$, свидетельствующими о реализации в нём существенной доли хрома в непарамагнитной форме. Заметим, что в отсутствие жёстких восстановительных условий синтеза такими ионами могут быть лишь $\mathrm{Cr}^{4+}$ и $\mathrm{Cr}^{6+}[5]$.

Отмеченные при описании табл. 2 различия в характере изменения значений $N_{1}, N_{2}$ и $I$ при замещении $\mathrm{Al}_{2} \mathrm{O}_{3}$ либо $\mathrm{B}_{2} \mathrm{O}_{3}$ на $\mathrm{SiO}_{2}$, а также $\mathrm{Y}_{2} \mathrm{O}_{3}$ на $\mathrm{Yb}_{2} \mathrm{O}_{3}$ можно связать с влиянием на оптические центры хрома неоднотипных изменений структуры каркаса стекла изза различия энергии сродства к кислороду алюминия, кремния и бора $\left(E_{\mathrm{Al-O}}>E_{\mathrm{Si}-\mathrm{O}}>E_{\mathrm{B}-\mathrm{O}}\right)$ и коорди- национной нестабильности ионов $\mathrm{Yb}^{3+}[23]$. В пользу такого объяснения свидетельствует и различное изменение значений $n$. Как видно из табл. 1 , частичное замещение $\mathrm{Al}_{2} \mathrm{O}_{3}$ либо $\mathrm{B}_{2} \mathrm{O}_{3} 5 \mathrm{~mol} \% \mathrm{SiO}_{2}$ понижает $n$ соответственно на 0.008 (cp. образцы 1 и 3) и 0.0017 (ср. образцы 8 и 10), а замещение $2 \mathrm{~mol} \% \mathrm{Y}_{2} \mathrm{O}_{3}$ на $\mathrm{Yb}_{2} \mathrm{O}_{3}$ на 0.004 (ср. образцы 1 и 8).

Хорошо известно, что ионы $\mathrm{Cr}^{3+}$ в оксидных стёклах характеризуются типичными для октаэдрических центров широкими спинразрешенными, но запрещёнными по симметрии абсорбционными полосами ${ }^{4} A_{2} \rightarrow{ }^{4} T_{1}\left(\lambda_{\max } \approx 420 \mathrm{~nm}\right)$ и и ${ }^{4} A_{2} \rightarrow{ }^{4} T_{2}\left(\lambda_{\max } \approx 610 \mathrm{~nm}\right) ;$ ионы $\mathrm{Cr}^{4+}$ (в тетраэдрической координации) широкой электродипольной абсорбционной полосой ${ }^{3} A_{2} \rightarrow{ }^{3} T_{1} \quad$ с $\lambda_{\max } \approx 620 \mathrm{~nm}$, слабой магнитодипольной полосой ${ }^{3} A_{2} \rightarrow{ }^{3} T_{2}$ вблизи $1 \mu \mathrm{m}$ и более слабым поглощением в области длиннее $1200 \mathrm{~nm}$, обусловленным антирезонансом Фано для переходов ${ }^{3} A_{2} \rightarrow{ }^{1} E \quad$ и $\quad{ }^{3} A_{2} \rightarrow{ }^{3} T_{2} \quad$ [24]; ионы $\mathrm{Cr}^{5+}$ широкой абсорбционной полосой при $\lambda_{\max } \approx 465 \mathrm{~nm}$ (в октаэдрическом окружении) [25] и полосами при $\lambda_{\max } \approx 670 \mathrm{~nm}$ и $1100 \mathrm{~nm}$ (в тетраэдрическом окружении) [26], а оксокомплексы $\left[\mathrm{CrO}_{4}\right]^{2-}$ - полосой переноса заряда $\mathrm{Cr}^{6+} \mathrm{O}^{2-}\left(3 d^{0} 2 p^{6}\right) \rightarrow \mathrm{Cr}^{5+} \mathrm{O}^{-}\left(3 d^{1} 2 p^{5}\right)$ при $\lambda_{\max } \approx 360 \mathrm{~nm}$ [25]. Поэтому с учётом изложенного можно полагать, что определяющий вклад в спектры поглощения образцов 1-14 на рис. 2 вносят полосы ${ }^{4} A_{2} \rightarrow{ }^{4} T_{1}$ и ${ }^{4} A_{2} \rightarrow{ }^{4} T_{2}$ ионов $\mathrm{Cr}^{3+}$. При этом в образце 8 , судя по малым значениям $I$ и $N_{1}+N_{2}$ (см. табл. 2) и отсутствию полосы при $\lambda \approx 360 \mathrm{~nm}$ (см. рис. 2 , кривая 8 ), существенная доля хрома реализуется в форме $\mathrm{Cr}^{4+}$. Что касается образца 15 то, исходя из $35 \%$ снижения интенсивности полосы ${ }^{4} A_{2} \rightarrow{ }^{4} T_{2}$, многократного увеличения полосы с $\lambda_{\max } \approx 360 \mathrm{~nm}$ и минимальных значений $N_{1}+N_{2}$ и $I$, доля его непарамагнитных центров $\left[\mathrm{CrO}_{4}\right]^{2-}$ сравнима с долей ионов $\mathrm{Cr}^{3+}$. В пользу такой ситуации свидетельствует и заметный $(\approx 10 \mathrm{~nm})$ коротковолновой сдвиг максимума „красной“ полосы поглощения (рис. 2, cр. кривые 1 и 15), указывающий на снижение доли $\mathrm{Cr}^{4+}$. Присутствие последнего, а также полиэдров $\left[\mathrm{CrO}_{4}\right]^{3-}$ в исследованных стёклах подтверждается спектрами ИК поглощения на рис. 3, интенсивность которых не противоречит результатам ЭПР-исследования. Существенно бо́льшая степень снижения поглощения в ближней ИК области по сравнению со снижением в полосе ${ }^{4} A_{2} \rightarrow{ }^{4} T_{2}$ ионов $\mathrm{Cr}^{3+}$ по мере ощелачивания стекла (ср. соответствующие кривые на рис. 3 и рис. 2) свидетельствует о первоочередном окислении ионов $\mathrm{Cr}^{4+}$ и $\mathrm{Cr}^{5+}$, что можно связать с меньшей стабильностью $3 d$-электронной конфигурации последних по сравнению c $\mathrm{Cr}^{3+}$, у которого она наполовину заполнена. Противоречие данного вывода увеличению $N_{1}$ в табл. 2 (ср. образцы 3-5 и 13-15) разрешается, если одновременно возрастает доля шестикоординированных ионов $\mathrm{Cr}^{5+}$. Примечательно также, что с уменьшением концентрации хрома доля $\mathrm{Cr}^{4+}$ и $\mathrm{Cr}^{5+}$ падает более быстрыми темпами (рис. 3, ср. кривые 3 и 2). 
В свете изложенного основной вклад в СЛ исследованных стекол должны вносить ионы $\mathrm{Cr}^{3+}$. Поэтому люминесценцию $\mathrm{Cr}$-содержащих стекол на рис. 4 (см. вставку) можно в первом приближении интерпретировать суперпозицией, запрещённой по симметрии, но разрешённой по спину полосы ${ }^{4} T_{2} \rightarrow{ }^{4} A_{2}\left(\lambda_{\max } \approx 820 \mathrm{~nm}\right)$ и узкой, запрещённой по спину и симметрии полосы ${ }^{2} E \rightarrow{ }^{4} A_{2}\left(\lambda_{\max } \approx 694 \mathrm{~nm}\right)$ таких ионов. В действительности разложение СЛ подобных стекол на индивидуальные составляющие выявляет ещё две слабых полосы с $\lambda_{\max } \approx 730$ и $940 \mathrm{~nm}$, интерпретации которых планируется посвятить отдельную работу. Здесь следует отметить, что четырёхкоординированные ионы $\mathrm{Cr}^{4+}$ и $\mathrm{Cr}^{5+}$ в ряде матриц демонстрируют достаточно эффективную широкополосную люминесценцию с $\lambda_{\max }$ в области $1.3-1.5 \mu \mathrm{m}[14,24,26]$. Отсутствие такой люминесценции в нашем случае, по-видимому, можно связать с эффективным разменом энергии метастабильных состояний этих ионов на высокочастотные колебания примесных ОН-групп и группировок $\mathrm{BO}_{3}$. Что касается полосы с $\lambda_{\max } \approx 550 \mathrm{~nm}$, то её можно приписать люминесценции $\mathrm{Cr}^{5+}$ в октаэдрическом окружении, а слабую интенсивность объяснить переносом возбуждений на ионы $\mathrm{Cr}^{3+}$, $\mathrm{Cr}^{4+}$ и четырёхкоординированные $\mathrm{Cr}^{5+}$.

Небольшое $(\approx 18 \%)$ снижение интенсивности люминесценции при увеличении концентрации $\mathrm{Cr}_{2} \mathrm{O}_{3}$ с 0.1 до 0.2 mass \% (рис. 4, ср. кривые 2 и 3), учитывая в разы меньшую долю $\mathrm{Cr}^{4+}$ и $\mathrm{Cr}^{5+}$ в малолегированном образце (рис. 3, ср. кривые 2 и 3), свидетельствует об относительно слабом концентрационном тушении люминесценции $\mathrm{Cr}^{3+}$. Заметим, что согласно литературным данным [27,28], такое тушение в стеклообразной матрице при концентрации $\mathrm{Cr}_{2} \mathrm{O}_{3} \leq 0.1$ mass \% практически отсутствует. Многократное (от 7 до 13 раз) ослабление люминесценции ионов хрома при введении в $\mathrm{Cr}-\mathrm{Si}$ содержащие стекла $2 \mathrm{~mol} \% \mathrm{Yb}_{2} \mathrm{O}_{3}$ свидетельствует об эффективной передаче возбуждений на ионы $\mathrm{Yb}^{3+}$. При этом большое различие в интенсивности люминесценции последних (рис. 4, ср. кривые 10-15) логично связать с различной долей ионов $\mathrm{Cr}^{4+}$ и $\mathrm{Cr}^{5+}$, которые выполняют роль тушителей люминесценции (как $\mathrm{Cr}^{3+}$, так и $\mathrm{Yb}^{3+}$ ) и внутренних фильтров, экранирующих полосы поглощения ионов $\mathrm{Cr}^{3+}$. Очевидно, именно малая доля $\mathrm{Cr}^{4+}$ и невысокая $\mathrm{Cr}^{5+}$ в образце 15 является причиной относительно большого значения квантового выхода его сенсибилизированной люминесценции $(\approx 32 \%)$. Заметим, что эта величина, несмотря на относительно высокую концентрацию примесных $\mathrm{OH}^{-}$групп $\left(k_{\mathrm{OH}} \approx 2.72 \mathrm{~cm}^{-1}\right)$, в 1.5 раза выше чем для стекла $50 \mathrm{SiO}_{2}-20 \mathrm{Al}_{2} \mathrm{O}_{3}-(30-x-y) \mathrm{CaF}_{2}-x \mathrm{CrF}_{3}-y \mathrm{YbF}_{3}$ [29]. С учётом зависимости вероятности тушения люминесценции $\mathrm{Yb}^{3+}$ от концентрации $\mathrm{OH}^{-}$-групп [13] можно прогнозировать, что снижение последней способно заметно увеличить значение $\eta$.

Более коротковолновое (на $10-20 \mathrm{~nm}$ ) положение полосы ${ }^{4} A_{2} \rightarrow{ }^{4} T_{2}$ ионов $\mathrm{Cr}^{3+}$ и бо́льшую крутизну её длинноволнового крыла в СВЛ исследованных стекол (рис. 5) по сравнению с ССО (рис. 2) можно объяснить влиянием внутреннего фильтра (ионов $\mathrm{Cr}^{4+}$ и $\mathrm{Cr}^{5+}$ ) и слабой сенсибилизацией люминесценции $\mathrm{Yb}^{3+}$ ионами $\mathrm{Cr}^{5+}$ в тетраэдрическом окружении. Появление в СВЛ щелочных стекол (рис. 5, кривые 13-15) явного плеча при $\lambda \approx 360 \mathrm{~nm}$ свидетельствует о сенсибилизации люминесценции ионов $\mathrm{Yb}^{3+}$ через полосу переноса заряда $\mathrm{Cr}^{6+} \mathrm{O}^{2-}\left(3 d^{0} 2 p^{6}\right) \rightarrow \mathrm{Cr}^{5+} \mathrm{O}^{-}\left(3 d^{1} 2 p^{5}\right)$. Однако эффективность такого процесса (судя по соотношению интенсивностей для кривых 13-15 в СВЛ и ССО) невелика. Что касается слабой структуры на длинноволновом крыле полосы ${ }^{4} A_{2} \rightarrow{ }^{4} T_{2}$ при $\lambda \approx 645$ и $680 \mathrm{~nm}$ в СВЛ, заметной также и в $\mathrm{CCO}$, то она обусловлена антирезонансом Фано для переходов ${ }^{4} A_{2} \rightarrow{ }^{2} E,{ }^{2} T_{1}$ и ${ }^{4} A_{2} \rightarrow{ }^{4} T_{2}$ [30].

Неэкспоненциальность кинетики затухания люминесценции ионов $\mathrm{Yb}^{3+}$ и существенно меньшие значения её средней длительности для приведенных в табл. 3 образцов стекол по сравнению со стеклом состава $(\mathrm{mol} \%) 8 \mathrm{Y}_{2} \mathrm{O}_{3}-2 \mathrm{Yb}_{2} \mathrm{O}_{3}-30 \mathrm{Al}_{2} \mathrm{O}_{3}-60 \mathrm{~B}_{2} \mathrm{O}_{3}$, для которого $\langle\tau\rangle \approx 500 \mu \mathrm{s}$ [13], подтверждает тушение люминесценции $\mathrm{Yb}^{3+}$ ионами $\mathrm{Cr}^{4+}$ и $\mathrm{Cr}^{5+}$. Особенно эффективно такое тушение, как видно из данной таблицы, осуществляется для образца 8, который хоть и характеризуется низким значением $k_{\mathrm{OH}}$ (табл. 1$)$, но обладает, как указано выше, высокой долей ионов $\mathrm{Cr}^{4+}$.

Значительное температурное тушение люминесценции ионов $\mathrm{Cr}^{3+}$ (рис. 6, кривые 3 и 5) логично объяснить увеличением вероятности туннельного перехода из колебательных подуровней состояния ${ }^{4} T_{2}$ на высоковозбуждённые подуровни основного состояния ${ }^{4} A_{2}$ по мере приближения к точке пересечения их адиабатических кривых. Существенное снижение эффективности такого тушения для $\mathrm{Cr}-\mathrm{Yb}$-содержащих стекол обусловлено конкурирующим с ним переносом возбуждений от $\mathrm{Cr}^{3+}$ на $\mathrm{Yb}^{3+}$ и слабым температурным тушением люминесценции последних. Заметим, что знание температурного хода интенсивности люминесценции подобных стекол представляется важным в плане их практического использования.

\section{Выводы}

Таким образом, в стёклах системы $\left(\mathrm{Y}_{1-x} \mathrm{Yb}_{x}\right)_{2} \mathrm{O}_{3}-\mathrm{Al}_{2} \mathrm{O}_{3}-\mathrm{B}_{2} \mathrm{O}_{3}-\mathrm{SiO}_{2}+\mathrm{Cr}_{2} \mathrm{O}_{3}+\mathrm{Na}_{2} \mathrm{O} \quad$ в отсутствие щёлочи хром реализуется в степени окисления $\mathrm{Cr}(\mathrm{III})-\mathrm{Cr}(\mathrm{V})$ с превалирующей долей $\mathrm{Cr}(\mathrm{III})$. Ощелачивание этих стекол сопровождается формированием центров $\mathrm{Cr}^{6+}$ за счёт окисления ионов хрома с более низким зарядом и в первую очередь четырёхкоординированных $\mathrm{Cr}^{4+}$ и $\mathrm{Cr}^{5+}$. Частичное замещение в матрице при прочих равных условиях $\mathrm{Al}_{2} \mathrm{O}_{3}$ на $\mathrm{SiO}_{2}$ сопровождается увеличением концентраций $\mathrm{Cr}^{5+}$ и изолированных сильно искажённых полиэдров $\left[\mathrm{CrO}_{6}\right]^{9-}$, при этом концентрация изолированных $\left[\mathrm{CrO}_{6}\right]^{9-}$ ромбической симметрии в сильном локальном поле незначительно снижается в стёклах без Yb и многократ- 
но возрастает при его наличии. При замещении $\mathrm{B}_{2} \mathrm{O}_{3}$ на $\mathrm{SiO}_{2}$ такой тенденции не наблюдается. Замещение $\mathrm{Y}$ на $\mathrm{Yb}$ также сопровождается перераспределением относительных концентраций оптических центров ионов хрома. Основной вклад в сенсибилизацию люминесценции ионов $\mathrm{Yb}^{3+}$ вносят ионы $\mathrm{Cr}^{3+}$, а ионы $\mathrm{Cr}^{4+}$ и в меньшей степени $\mathrm{Cr}^{5+}$ играют роль тушителя люминесценции и внутреннего фильтра. Дополнительный вклад в люминесценцию $\mathrm{Yb}^{3+}$ вносит её сенсибилизация через полосу переноса заряда в $\mathrm{Cr}(\mathrm{VI})$. Снижение доли ионов $\mathrm{Cr}^{4+}$ и $\mathrm{Cr}^{5+}$ путём ощелачивания стекла, оптимизация концентрации хрома и иттербия, а также дегидратация способны поднять квантовый выход сенсибилизированной люминесценции ионов $\mathrm{Yb}^{3+}$ заметно выше достигнутых 32\%. $\mathrm{Cr}-\mathrm{Yb}$-содержащие стекла характеризуются существенно меньшим температурным тушением люминесценции, чем Cr-содержащие.

\section{Финансирование работы}

Работа поддержана Белорусским республиканским фондом фундаментальных исследований (гранты № Ф18Р-039 и № Ф19УЗБГ-005), Министерством науки и высшего образования России (грант FSSM2020-0003) и Министерством инновационного развития Узбекистана (грант MRB-AN-2019-2021).

\section{Конфликт интересов}

Авторы заявляют, что у них нет конфликта интересов.

\section{Список литературы}

[1] L.J. Andrews, B.C. McCollum, A. Lempicki. J. Lumin., 24-25, 877 (1981). DOI: 10.1016/0022-2313(81)90109-5

[2] Н.В. Данильчук, С.Г. Лунтер, Ю.П. Николаев, Г.Т. Петровский, Ю.К. Фёдоров, В.Н. Шаповалов. ДАН СССР, 266 (5), 1115 (1982).

[3] S.G. Lunter, A.G. Murzin, M.N. Tolstoi, Yu.K. Fedorov, V.A. Fromzel'. Sov. Phys. Sol. State, 14 (1), 66 (1984).

[4] W.J. Miniscalco. J. Lumin., 31-32, 830 (1984). DOI: $10.1016 / 0022-2313(84) 90139-X$

[5] N. Iwamoto, Y. Makino. J. Non-Cryst. Sol., 41 (2), 257 (1980). DOI: 10.1016/0022-3093(80)90171-4

[6] M.A. Hassan, F. Ahmad, Z.M. Abd El-Fattah. J. Alloys Compd., 750, 320 (2018).

DOI: $10.1016 /$ j.jallcom.2018.03.351

[7] T. Murata, M. Torisaka, H. Takebe, K. Morinaga. J. Non-Cryst. Sol., 220 (2-3), 139 (1997). DOI: 10.1016/S0022-3093(97)00264-0

[8] R. Lachheb, A. Herrmann, K. Damak, C. Rüssel, R. Maâlej. J. Lum., 186, 152 (2017). DOI: 10.1016/j.jlumin.2017.02.030

[9] Г.Е. Малашкевич, Г.И. Семкова, А.В. Семченко, П.П. Першукевич, И.В. Прусова. Письма в ЖЭТФ, 88 (11), 773 (2008). [G.E. Malashkevich, G.I. Semkova, A.V. Semchenko, P.P. Perhukevich, I.V. Prusova. JETP Letters, 88 (11), 740 (2008). DOI: 10.1134/S0021364008230082].

[10] M. Herren, H. Nishiuchi, M. Morita. J. Chem. Phys., 101, 4461 (1994). DOI: $10.1063 / 1.467430$
[11] Sh. Payziyev, Kh. Makhmudov. J. Ren. Sust. En., 8 (1), 015902-1 (2016). DOI: 10.1063/1.4939505

[12] G.E. Malashkevich, V.N. Sigaev, N.V. Golubev, E.Kh. Mamadzhanova, A.A. Sukhodola, A. Paleari, P.D. Sarkisov, A.N. Shimko. Mat. Chem. Phys., 137 (1), 48 (2012). DOI: 10.1016/j.matchemphys.2012.07.055

[13] G.E. Malashkevich, V.V. Kouhar, E.V. Pestryakov, V.N. Sigaev, N.V. Golubev, M.Z. Ziyatdinova, A.A. Sukhodola. Opt. Mat,, 76, 253 (2018). DOI: 10.1016/j.optmat.2017.12.042

[14] W. Strek, P.J. Deren, E. Lukowiak, J. Hanuza, H. Drulis, A. Bednarkiewicz, V. Gaishun. J. Non-Cryst. Sol., 288 (1-3), 56 (2001). DOI: 10.1016/S0022-3093(01)00610-X

[15] Cz. Koepke, K. Wisniewski, M. Grinberg, F. Rozploch. J. Phys.: Condens. Matter., 14 (45), 11553 (2002). DOI: $10.1088 / 0953-8984 / 14 / 45 / 301$

[16] V.K. Zakharov, D.M. Yudin. Sov. Phys. Sol. State, 7, 1267 (1967).

[17] A. Srinivasa Rao, J. Lakshmana Rao, R. Ramakrishna Reddy, T.V. Ramakrishna Rao. Opt. Mat., 4 (6), 717 (1995). DOI: 10.1016/0925-3467(95)00040-2

[18] R.P. Sreekanth Chakradhar, J. Lakshmana Rao, G. Sivaramaiah, N.O. Gopal. Phys. Stat. Sol. (B), 242 (14), 2919 (2005). DOI: 10.1002/pssb.200540100

[19] T. Lesniewski, B.V. Padlyak, J. Barzowska, S. Mahlik, V.T. Adamiv, Z. Nurgul, M. Grinberg. Opt. Mat., 59, 120 (2016). DOI: 10.1016/j.optmat.2016.01.008

[20] M.R. Ahmed, K.Ch. Sekhar, A. Hameed, M.N. Chary, Md. Shareefuddin. Int. J. Modern Physics B, 32 (8), 18500951 (2018). DOI: 10.1142/S0217979218500959

[21] C. Lin, J. Liu, L. Han, H. Gui, J. Song, C. Li, T. Liu, A. Lu. J. Non-Cryst. Sol., 500, 235 (2018). DOI: $10.1016 /$ j.jnoncrysol.2018.08.004

[22] B. Srinivas, B. Srikantha Chary, Abdul Hameed, M. Narasimha Chary, Md. Shareefuddin. Opt. Mat., 109, 110329 (2020). DOI: 10.1016/j.optmat.2020.110329

[23] Г.А. Бандуркин, Б.Ф. Джуринский, И.В. Тананаев. Особенности кристаллохимии соединений редкоземельных элементов. (Наука, Москва, 1984).

[24] X. Feng, S. Tanabe. Opt. Mat., 20 (1), 63 (2002). DOI: 10.1016/S0925-3467(02)00048-4

[25] Cz. Koepke, K. Wisniewski, M. Grinberg. J. Alloys Comp., 341 (1-2), 19 (2002). DOI: $10.1016 / \mathrm{S} 0925-8388(02) 00091-9$

[26] P. Gerner, K. Kramer, H.U. Gudel. J. Lumin., 102-103, 112 (2003). DOI: 10.1016/S0022-2313(02)00476-3

[27] L.J. Andrews, A. Lempicki, B.C. McCollum. J. Chem. Phys., 74 (10), 5526 (1981). DOI: 10.1063/1.440915

[28] И.Б. Арцыбышева, С.Г. Лунтер, Н.Т. Тимофеев, Ю.К. Фёдоров. Физика и химия стекла, 16, 625 (1990).

[29] H. Fu, Sh. Cui, Q. Luo, X. Qiao, X. Fan, X. Zhang. J. NonCryst. Sol., 358 (9), 1217 (2012). DOI: $10.1016 /$ j.jnoncrysol.2012.02.024

[30] A. Lempicki, L. Andrews, S.J. Nettel, B.C. McCollum. Phys. Rev. Lett., 44 (18), 1234 (1980). DOI: $10.1103 /$ PhysRevLett.44.1234 